\title{
PERAN POS BANTUAN HUKUM 'AISYIYAH KALIMANTAN TENGAH TERHADAP PERLINDUNGAN HUKUM PEREMPUAN DAN ANAK DIMASA PANDEMI COVID- 19
}

\section{Sanawiah \\ Rita rahmaniati}

Universitas Muhammadiyah Palangkaraya, Palangka Raya, Central Kalimantan, Indonesia

Email :

sanawiah.sanaw@gmail.com rahmaniatirita@gmail.com

\section{Kata Kunci:}

Peran, Posbakum 'Aisyiyah, Covid-19

\section{Keywords:}

Role, Posbakum 'Aisyiyah, 'Aisyiyah Legal Aid Post, Covid-19

\begin{abstract}
Abstrak
Penelitian ini bertujuan untuk mengetahui peranan pos bantuan hukum (Posbakum) 'Aisyiyah di Kalimantan Tengah dalam pendampingan hukum dan mendukung kebijakan pemerintah kota Palangka Raya terhadap perlindungan hukum bagi perempuan dan anak di tengah pandemi covid-19. Metode penelitian ini menggunakan pendekatan deskriptif kualitatif bertujuan untuk mendeskripsikan perilaku orang, dengan menyoroti peristiwa di lapangan, serta kegiatan-kegiatan tertentu secara terperinci dan mendalam. Hasil penelitian ini untuk mendeskripsikan peranan bantuan hukum (POSBAKUM Aisyiyah) berupa kegiatan pendampingan hukum terhadap klien mulai dari tahap pelaporan sampai dengan tahap pendampingan beracara dipengadilan oleh pengacara Posbakum 'Aisyiyah. Rata - rata perkara yang ditangani yaitu kekerasan dalam rumah tangga (KDRT), tidak memberi nafkah, meninggalkan istri dan anak-anak, dengan wanita lain.
\end{abstract}

\section{PENDAHULUAN}

'Aisyiyah adalah salah satu organisasi wanita otonom keagamaan terbesar di Indonesia yang didirikan di Yogyakarta pada 27 Rajab $1426 \mathrm{H}$ bertepatan dengan 19 Mei
1917 oleh Kiai Haji Ahmad Dahlan. Gerakan 'Aisyiyah dari waktu ke waktu terus berkembang dan memberikan manfaat bagi peningkatan dan kemajuan harkat dan martabat perempuan Indonesia. Majelis 
Hukum dan HAM Pimpinan Pusat (PP) 'Aisyiyah membentuk Pos Bantuan Hukum (POSBAKUM) 'Aisyiyah dan sudah ada diberbagai Provinsi dari Aceh hingga Papua. Posbakum 'Aisyiyah sudah melakukan pendampingan baik litigasi maupun non litigasi. Bantuan hukum dapat diterapkan untuk kasuskasus terkait perkawinan, waris, hak perempuan dan anak. Kasus-kasus pengabaian hak-hak perempuan dalam perceraian, nafkah iddah, mut'ah, harta gono-gini paling dominan di hukum perdata. Salah satu bentuk amal usaha yang didirikan Majelis Hukum dan HAM pada Pimpinan Wilayah Aisyiyah Kalimantan Tengah adalah dengan membentuk Pos Bantuan Hukum (POSBAKUM) 'Aisyiyah Kalimantan Tengah.

POSBAKUM 'Aisyiyah Kalimantan

Tengah. Didirikan atas dasar surat keputusan

Pimpinan Wilayah 'Aisyiyah Kalimantan

Tengah, Nomor 29/SK-PWA/A/IX/2019.

Tentang Pendirian Pos Bantuan Hukum (POSBAKUM) 'Aisyiyah Kalimantan Tengah, tanggal I2 Muharram I44I H atau bertepatan dengan tanggal 12 September 2019, diresmikan oleh Kantor Wilayah Kementerian Hukum dan HAM Kalimantan Tengah, pada tanggal II syafar |44I H, atau bertepatan dengan tanggal 10 Oktober $2019 \mathrm{M}$.

POSBAKUM 'Aisyiyah
berperan aktif membantu
pemerintah durut
pencegahan
(COVID-19). Terdapat banyak kebijakan

Pemerintah sebagai bentuk pencegahan dan antisipasi penyebaran Covid-19, salah satu kebijakan yang dilakukan Pemerintah Kota Palangka Raya adalah dengan pemberlakuan PSBB pada bulan Mei 2020 yang lalu dan
PPKM pada bulan Januari 2021. Pembatasan kegaiatan masyarakat ini tentu memiliki dampak yang sangat besar pada berbagai aspek, baik aspek pendidikan, ekonomi, kesehatan maupun lainnya.

Hasil survei pada wanita yang berprofesi sebagai lbu rumah tangga di kota Palangka Raya, ditemukan bahwa adanya kegelisahan dalam menghadapi situasi pademi Covid-19 saat ini. Adanya keluhan ibu rumah tangga terhadap beban tugas sekolah anak-anak yang menuntut pendampingan, ditambah dengan biaya kouta internet serta tarif listrik yang meningkat seiring dengan lebih banyak kegiatan-kegiatan yang dilakukan dirumah, dan meningkatnya harga sembako serta obat-obatan. Kebutuhan semakin meningkat yang tidak disertai dengan peningkatan pendapatan menjadi beban tersendiri bagi suami sebagai kepala rumah tangga. Hal ini kemudian dapat memicu terjadinya ketidakstabilan ekonomi rumah tangga dan memicu kekerasan dalam Rumah Tangga (KDRT). Banyaknya laporan dan permintaan perlindungan hukum serta pendampingan oleh korban KDRT. Peran POSBAKUM 'Aisyiyah sangat dibutuhkan dalam membantu pemerintah dan masyarakat dalam perlindungan hukum terhadap perempuan dan anak di tengah Pandemi Covid -19 khususnya masyarakat Kalimantan Tengah. 
Berdasarkan latar belakang inilah peneliti tertarik untuk melakukan penelitian terkait Peran Pos Bantuan Hukum 'Aisyiyah Kalimantan Tengah Terhadap Perlindungan Hukum Perempuan dan Anak dimasa Pandemi Covid-19. Adapun rumusan masalah dalam penelitian ini adalah:

I. Bagaimana Peranan Posbakum 'Aisyiyah Kalimantan Tengah dalam pendampingan di masa Pandemi Covid - 19?

2. Bagaimana kebijakan pemerintah kota Palangkaraya terhadap perlindungan hukum perempuan dan anak di tengah pandemi covid-19?

Adapun tujuan yang hendak dicapai dalam penelitian ini adalah untuk:

I. Mengetahui Peranan Posbakum 'Aisyiyah Kalimantan Tengah dalam pendampingan di masa Pandemi Covid - 19.

2. Mendeskripsikan kebijakan pemerintah kota Palangkaraya terhadap perlindungan hukum perempuan dan anak di tengah pandemi covid-19?

Pos Bantuan Hukum (POSBAKUM) 'Aisyiyah Kalimantan Tengah memiliki Visi dan Misi, sebagai berikut:

VISI IDEAL : Tegakkan Keadilan dan Terwujudnya Masyarakat Damai.

VISI PENGEMBANGAN: Tercapainya Pos Bantuan Hukum (Posbakum) 'Aisyiyah yang mengarah pada pelayanan yang jujur dan profesional dan pengembangan dakwah amar ma'ruf nahi munkar.

MISI : Misi Pos Bantuan Hukum (Posbakum) 'Aisyiyah Kalimanan Tengah diwujudkan dalam bentuk program dan kegiatan di masa Pandemi covid 19, meliputi:

I. Penyuluhan Hukum dan Konseling, Pelatihan paralegal untuk meningkatkan kesadarakan hukum masyarakat tentang nilai-nilai hukum.

2. Pelayanan hukum - konsultasi hukum, pendampingan dan pembelaan diluar dan didalam pengadilan bagi kelompok masyarakat miskin, dan korban ketidakadilan lainnya;

3. Kajian, publikasi informasi dan dokumentasi.

Perlindungan dalam ilmu hukum adalah suatu bentuk pelayanan yang wajib dilaksanakan oleh aparat penegak hukum atau aparat keamanan untuk memberikan rasa aman, baik fisik maupun mental, kepada korban dan sanksi dari ancaman, gangguan, teror, dan kekerasan dari pihak manapun yang diberikan pada tahap penyelidikan, penyidikan, penuntutan, dan atas pemeriksaan di sidang pengadilan. Pengertian Perlindungan adalah tempat berlindung, hal (perbuatan dan sebagainya) memperlindungi. Perlindungan yang tertuang dalam Peraturan Pemerintah No.2 Tahun 2002 adalah suatu bentuk 
pelayanan yang wajib dilaksanakan oleh aparat penegak hukum atau aparat keamanan untuk memberikan rasa aman baik fisik maupun mental, kepada korban dan saksi, dari ancaman, gangguan, teror, dan kekerasan dari pihak manapun, yang diberikan pada tahap penyelidikan, penyidikan, penuntutan, dan atau pemeriksaan di sidang pengadilan.

Palangka Raya sebagai ibukota Propinsi Kalimantan Tengah, salah satu kota yang mengalami peninggkatan kasus Covid cukup Signifikan. Peningkatan penyebaran kasus Covid-19 di kota Palangka Raya (data per tanggal 20 Juni 2020 I44 orang positif, 59 sembuh dan 8 orang meninggal dunia. Hal ini membuat Walikota Palangkaraya bekerjasama dengan Dinas terkait membuat beberapa kebijakan sebagai upaya pemutusan rantai penyebaran covid-19 diantaranya meliburkan kegiatan pembelajaran pada tingkat satuan pendidikan, penyemprotan disinfektan, sosialisasi penanggulangan Covid-19, pemeriksaan penumpang dan kendaraan yang melintasi perbatasan wilayah Palangka Raya. Namun, kebijakan tersebut dirasa dapat kurang menekan angka penyebaran Covid-19, oleh sebab itu pemerintah kota melakukan upaya lainnya yaitu menerapkan PSPB tahap I dan melakukan rapid tes massal ditempattempat umum seperti pasar dan tempat keramaian lainnya.
Kebijakan yang dilakukan pemerintah Kota Palangka Raya menimbulkan polemik di masyarakat. Beberapa kasus yang terjadi sebagai dampak dari wabah Covid-19 seperti penyebaran informasi terkait Covit-19 melalui media sosial yang terkadang berakhir dengan pihak kepolisian, over diagnosa dokter di rumah sakit, menyebabkan keresahan semakin bertambah, penolakan warga terhadap isolasi mandiri dan penguburan jenazah Covid-19 serta kasus lainnya. Selain itu, kebijakan pemerintah kota Palangkaraya terkait diliburkannya pembelajaran pada tingkat satuan pendidikan juga berdampak pada orang tua dan anak-anak sekolah yang merasa terbebani dengan tugas- tugas yang diberikan guru sehingga juga berdampak pada psikologis anak.

\section{Metode penelitian}

$$
\text { Penelitian ini menggunakan }
$$
pendekatan deskriptif kualitatif. Lokasi penelitian akan dilakukan di Pos Bantuan Hukum (POSBAKUM) 'Aisyiyah Kalimantan Tengah dan di Kota Palangka Raya. Subjek penelitian Klien POSBAKUM 'Aisyiyah Kalimamtan Tengah sebanyak 7 orang dan Pemerintah Kota Palangka Raya selaku pembuat kebijakan 2 orang. Jenis data yang diperlukan dalam penelitian ini adalah data primer, dan data sekunder. Data primer (data dasar) adalah data yang langsung diperoleh dari masyarakat. Sedangkan data sekunder adalah bahan- bahan perpustakaan, jurnal- 
jurnal, makalah, media massa cetak dan elektronik yang memuat tulisan-tulisan pakar hukum yang berkaitan dengan Peran Posbakum'Aisyiyah dalam perlindungan hukum terhadap perempuan dan anak ditengah Pandemi COVID-19. Data pendukung dimaksud diperoleh melalui pengumpulan data dengan mengunakan teknik wawancara dan observasi. Teknik Pengumpulan data dalam penelitian ini adalah menggunakan teknik wawancara, observasi dan dokumentasi. Adapun teknik analisa data, meliputi a) Reduksi Data, b) Sajian Data (display data) c) Verifikasi dan d) Simpulan Data.

\section{Hasil dan pembahasan}

Peran Pos Bantuan Hukum 'Aisyiyah Kalimantan Tengah dalam upaya membantu program pemerintah dibidang hukum dan membantu masyarakat yang mengalami perkaraperkara hukum terutama masyarakat tidak miskin, apalagi disaat ini dengan adanya wabah Corona yang melanda bangsa dan Negara.

\section{Peranan Posbakum 'Aisyiyah Kalimantan Tengah dalam pendampingan di masa Pandemi Covid - 19}

$$
\text { Posbakum 'Aisyiyah Kalimantan }
$$

Tengah melaksanakan Undang-Undang Nomor 16

Tahun $201 \mathrm{I}$ tentang bantuan Hukum Gratis Bagi masyarakat miskin. Keberadaan (POSBAKUM) Pos Bantuan Hukum 'Aisyiyah Kalimantan Tengah semenjak diresmikan pada tanggal II Oktober 2019 dan mulai beraktifitas bulan Mei 2020. Tercatat kasus masuk dari bulan Mei sampai dengan November 2020 lebih dari ada 25 kasus berkaitan erat dengan kasus Perempuan dan Anak. Beberapa contoh kasus yang masuk pada layanan Posbakum sebagai berikut:

\section{Kasus I}

Pada masa pandemi Covid-19 ini sebagian masyarakat ketakutan berobat ke rumah sakit atau puskesmas. Akibat ketakutan ini menajdikan pengoabatan alternative menjadi pilihan. Salah satunya beobat melalui orang pintar (oknum yang mengaku Ustadz). Oleh Oknum Ustadz tersebut, para pasien sakit dianggap sebagai penyakit non medis, sehingga perlu di Ruqyah' dengan cara yang tidak umum dilakukan pada kabanyakan metode Ruqyah. Ternyata pasien diberi pengobatan dengan cara yang tidak pantas (pelecehan seksual). Seorang Remaja (ES) dan beberapa lbu-ibu muda menjadi korban pelecehan seksual oleh oknum mengaku ustadz tersebut datang ke POSBAKUM Aisyiyah pada bulan Mei tahun 2020 untuk meminta perlindungan hukum. Bentuk bantuan hukum dari

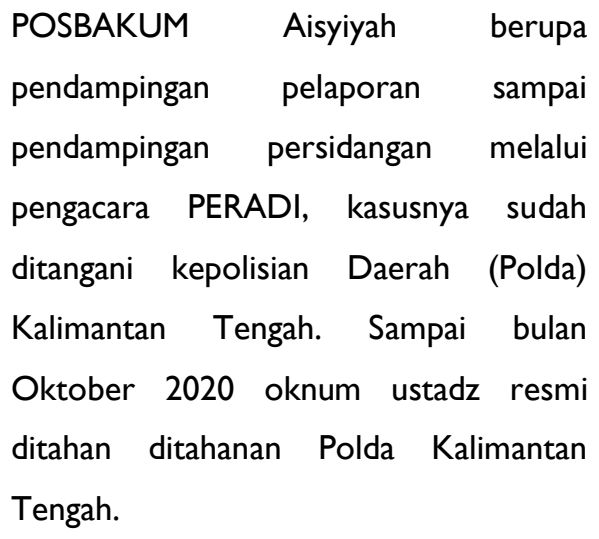

\section{Kasus 2}


Seorang ibu dengan inisial $\mathrm{RH}$ selama ini mengalami kekerasan dalam Rumah tangga oleh suami. 3 tahun terakhir suami memiliki banyak wanita lain dan sering melakukan kekerasan fisik terhadap ibu RH. Suami ibu RH sudah I tahun terakhir tidak lagi menafkahi lahir bathin kepada ibu $\mathrm{RH}$ yang juga memiliki seorang balita. Pada tanggal 25 September tahun 2020, Ibu RH datang ke Posbakum 'Aisyiyah Kalimantan Tengah mengadukan permasalahannya dan meminta bantuan untuk penyelesaiannya. Bentuk bantuan hukum dari Aisyiyah berupa pendampingan proses cerai talaq oleh suaminya, pendampingan Klien dalam persidangan di pengadilan Agama Kota Palangkaraya. Bantuan pengacara dari POSBAKUM Aisyiyah.

\section{Kasus 3}

Seorang ibu dengan inisial NR 3 orang anak yang ditinggalkan suaminya sekitar 4 tahun dengan wanita simpanan. Bentuk bantuan hukum dari Aisyiyah berupa pendampingan pendaftaran perceraian sampai pendampingan persidangan di pengadilan Agama kota Palangkaraya. Bantuan pengacara dari POSBAKUM Aisyiyah, selanjutnya pada tanggal II Juni 2020 nama WR memiliki 3 orang anak ditinggalkan suaminya sekitar 5 tahun dengan wanita simpanan. Kasus

perceraian. selesai pada putusan Pengadilan Agama Palangka Raya, dengan salinan putusan nomor 302/Pdt.G/2020/PA.Plk, tanggal 19

Oktober 2020. Bentuk bantuan hukum dari Aisyiyah berupa pendampingan pendaftaran perceraian sampai pendampingan persidangan di pengadilan Agama kota Palangkaraya. Bantuan pengacara dari POSBAKUM Aisyiyah.

\section{Kasus 4}

Seorang ibu berinisial RSM memiliki 3 orang anak meminta bantuan hukum ke posbakum karena ditinggalkan suaminya sekitar II tahun dengan wanita simpanan, kasus perkara sedang dalam penyidikan Kapolres Kuala Kapuas. Bentuk bantuan hukum dari Aisyiyah berupa pendampingan pelaporan ke Polres Kuala Kapuas.

\section{Kasus $\mathbf{5}$}

Kasus selanjutnya yang Posbakum 'Aisyiyah terima pada tanggal I3 November 2020, atas nama NA, menikah pada bulan Maret 2020, tempat tinggal di Kota Palangka Raya, dengan seorang polisi sekarang bertugas di kec. Pagatan Kab. Katingan. Kasus KDRT, perkara sudah masuk ke Pengadilan agama yang didampingi 3 (tiga) orang 


\begin{tabular}{|c|c|c|c|}
\hline pengacara & \multicolumn{2}{|c|}{ Posbakum } & 'Aisyiyah \\
\hline Kalimantan & Tengah & dan & putusan \\
\hline Pengadilan & Agama & sudah & diterim \\
\hline dengan & salinan & putusan & \\
\hline
\end{tabular}

Desember 2020.

\section{Keberadaan dan peran}

Lembaga bantuan hukum tidak banyak masyarakat yang mengetahuinya, terutama di Kalimantan Tengah. Sebagian besar masyarakat mengetahui masalah bantuan hukum hanya bagi kalamgan ekonomi menengah keatas, sedangkan bagi kalangan ekonomi kebawah yang tidak memiliki kemampuan ekonomi secara materil tidak mampu menunjuk advokat sebagaimana yang dilakukan oleh kelompok yang memiliki kemampuan secara ekonomi. Padahal, menjamin hak masyarakat mendapatkan bantuan hukum khususnya bagi masyarakat miskin adalah kewajiban dari negara. Hal ini sebagai konsekuensi logis dan pengakuan negara yang mengatakan "segala warga negara bersamaan kedudukannya di depan hukum dan pemerintah dan wajib menjunjung hukum dan pemerintahan itu dengan tidak ada kecualinya. Kemudian dalam Pasal 34 ayat (II) UUD 1945 menegaskan "Fakir miskin dan anak-anak yang telantar dipelihara oleh Negara”. Hal ini secara ekstensif dapat ditafsirkan bahwa negara bertanggung jawab memberikan perlindungan dan pengakuan terhadap hak-hak fakir miskin. Undang-Undang Nomor 12 Tahun 2005 tentang Kovenan Internasional Hak-Hak Sipil dan Politik mengakui hak atas bantuan hukum dan hak atas Advokat dan memerintahkan negara untuk menyediakan Advokat yang memberikaan bantuan hukum secara efektif untuk masyarakat miskin ketika kepentingan keadilan mensyaratkannya.

Berdasarkan wawancara dengan beberapa sumber, umumnya mereka tidak mengetahui secara langsung keberadaan Posbakum Aisyiyah Kalimanta Tengah, namun setelah dilakukan pendekatan ke masyarakat dan peran media social tentang bantuan hukum oleh Posbakum, masyarakat sebagian sudah banyak yang mengenal Posbakum Aisyiyah.

Klien mengetahui keberhasilan posbakum Aisyiyah Kalimantan Tengah dari kenalan orangtua nya, dari keluarga, dari tetangga, dan dari pengelola Posbakum Aisyiyah.

Menurut Klien, peran Posbakum Aisyiyah Kalimantan Tengah sebagai Tempat Pengaduan Perceraian (NA), Dapat memberikan bantuan hukum terutama masalah rumah tangga saya dan membatu hak bagi penerima bantuan hukum untuk mendapatkan akses sebuah keadilan hukum (RS). Posbakum Aisyiyah adalah pos bantuan 
hukum yang sebagian besar dikelola oleh ibu-ibu Aisyiyah (LR). Tempat atau wadah mengadukan hukum bagi masyarakat yang tidak paham hukum, untuk mendapatkan akses keadilan hukum (WR). Tempat untuk membantu orang yang kurang mampu dalam permasalahan hukum (IN). Aisyiyah adalah tempat untuk membantu orangorang yang bermasalah hukum, yang kurang mampu (RH). Wadah pengaduan, konsultasi hukum (LL).

\section{Kemudian dilanjutkan} dengan pengetahuan masyarakat tentang apa saja bentuk layanan yang diberikan Posbakum, menurut Klien posbakum memberikan layanan Konsultasi hukum tentang perceraian,yang memberikan, Memberikan solusi dalam masalah rumah tangga semua yang perlu dengan bantuan hukum, Konsultasi, Pendampingan, Penyelesaian perkara (NA, RS, LR, WR, IN, RH, LL).

Pelayan bantuan hukum tentu memiliki prosedur layanan, untuk membantu proses penyelesaiannya. Alur pelayanan Posbakum sebagian besar masyarakat yang menjadi klien telah mengetahuinya setelah proses bantuan berjalan.

Alur layanan Posbakum dengan cara datang ke Posbakum lalu menceritakan keluhan, maka di bantu oleh pihak posbakum dengan tahapan pendaftaran, mengisi identitas, konsultasi masalah, tindakan/ pendampingan, penyelesaian (NA, RS, LR, WR, IN, RH, LL).

Selama
POSBAKUM juga mendampingan
pengacara. Menurut Klien Pengacara
pengacara sangat membantu untuk
menyelesaikan perceraian saya (NA).
menyelesaikan masalah hukum yang saya hadapi, sangat baik, ramah, Pengacara membantu dengan baik ( RS, LR, WR, IN, RH, LL). . Tidak ada biaya yang
dikenakan kepada klien pada proses
bantuan hukum. Penyelesaian perkara
berakhir pada ranah hukum ataupun
secara kekeluargaan.

Menurut Klien, tidak ada hambatan/ kendala yang dihadapi klien saat pendampingan oleh Posbakum dan layanan bantuan hukum yang diberikan oleh POSBAKUM Aisyiyah sangat memuaskan Secara umum, Responden memberikan tanggapan positif terhadap peran Posbakum di masyarakat, kebanyakan dari mereka beranggapan pelayanan Posbakum Aisyiyah adalah baik, karena dapat membantu masyarakat yang hendak menyelesaikan perkaranya terutama masyarakat tidak 
mampu dan masih belum faham dengan proses hukum. Peran Posbakum sangat membantu penyelesaian hukum di masyakarat terutama di masa pandemi covid -19 yang menjadi korban kekerasan fisik mapun non fisik. Penyelesaian hukum dengan bantuan Posbakum memuaskan bagi klien. Peran Posbakum berdasarkan hasil wawancara dengan pimpinan Posbakum Aisyiyah, sebagai berikut:

Posbakum, Aisyiyah Kalteng adalah salah satu amal usaha PWA Kalteng, dibawah Majelis Hukum dan Ham PWA Kalteng bertujuan membantu Program Pemerintah dibidang Pelayanan Hukum. (NH)

Posbakum dikenal masyarakat melalui mulut kemulut, melalui media sosial, penempatan Banner dan Brosur Pengadilan Agama Palangka Raya, penyuluhan kepada masyarakat, dari para Pengurus, Sosial media facebook dan website Kementerian Hukum dan HAM Wilayah Kalteng dan kegiatan non litigasi seperti penyuluhan hukum sosialisasi bantuan hukum kepada masyarakat serta sosialisasi kepada pengajian ibu-ibu.

$$
\text { Untuk mempermudah }
$$

layanan, alur bantuan hukum sangat mudah Klien cukup mendaftar di meja pendaftaran, Konsultasi dengan petugas yang membidangi, Dilanjutkan ke meja tindakan, Perkara klien dilanjutkan kepada pendampingan Pengacara atau diselesaikan secara musyawarah.

Layanan di POSBAKUM di upayakan optimal, konsultasi hukum gratis, bantuan untuk masyarakat miskin gratis, pendampingan klien tidak mampu yang sampai proses penyelesaian hukum ke PA atau PN dikenakan biaya sesuai dengan kesepakatan klien dan pengacara. Sejak Pandemi di kota Palangka Raya per bulan Maret tahun 2020,jumlah kasus yang di tangani sebanyak Ada 32 kasus. Perkara-perkara yang masuk di Posbakum meliputi Perceraian, KDRT, pelecahan seksual, sengketa warisan, Pencemaran Lingkungan oleh perusahaan Air Minum Daerah Kota Palangka Raya, Penelantaran Karyawan oleh Perusahan Sawit, kreditor, dan penggelapan. Tidak semua kasus berakhir dengan jalur hukum, ada beberapa diantaranya melalui jalur kekeluargaan.

Untuk memperkuat bentuk layanan, POSBAKUM melakukan kerjasama dengan pihak ke-3 misalnya Lawyer atau dinas atau ormas lainnya bahkan saat ini sedang proses persiapan akreditasi. Kesan Klien terhadap Posbakum, POSBAKUM Aisyiyah sangat membantu masyarakat, membuat percaya diri karena ada pendampingan, menambah wawasan. Posbakum agar lebih disosialisasikan lagi kemasyarakat, agar banyak orang tahu dan minta bantuan menyelesaikan masalah hukumnya. 
Jadi, menurut pengelola

Posbakum 'Aisyiyah sendiri memiliki peranan yang sangat membantu masyarakat dalam perkara yang diselesaikan secara hukum maupun tidak. Peranan Posbakum sangat dirasa bagi pelapor dengan ekonomi menengah ke bawah. Walaupun demikian, masih ada faktor penghambat Posbakum Aisyiyah yaitu belumnya terakreditasi, karena layanan pendaftaran Akreditasi secara online tahun 2020 belum dibuka oleh Kemenkum dan HAM Pusat, sehingga gerak dan aktivitasnya masih terbatas serta belum ada kerja sama dengan pihak ke-3 yang mampu mendanai kegiatan layanan gratis bagi Posbakum Aisyiyah ini dapat berjalan dengan baik dan lancar. Untuk kegiatan Non Litigasi, POSBAKUM 'Aisyiyah berkerjasama dengan Kemenkum dan HAM Wilayah Kalimantan Tengah, mengadakan sosilaisasi bantuan hukum gratis kepada mahasiswa, orang tua murid, penyuluhan-penyuluhan hukum ke pada masyarakat terutama tentang pembinaan keutuhan rumah tangga dengan memberikan penyuluhan peningkatan ketahan keluarga melalui pemahaman terhadap ajaran-ajaran agama, dalam upaya mewujudkan keluarga shakinah mawadhah warahmah.
A. Kebijakan Pemerintah kota Palangka Raya terhadap perlindungan hukum perempuan dan anak di tengah pandemi covid- 19.

Kebijakan yang dilakukan pemerintah Kota Palangka Raya, dalam upaya membantu masyarakat yang terdampak Covid-19, sebagimana yang kami lakukan dengan Wawancara bersama Kepala Dinas Pengendalian Penduduk, KB, Pemberdayaan, Perempuan Perlindungan Anak dan Pemberdayaan, Masyarakat (PPKBP3APM) Kota Palangka Raya. Saat ini Dinas PPKBP3APM sedang membantu perawatan anak usia 5 tahun korban kekerasan seksual oleh pria berusia 75 tahun yang merupakan tetangganya sendiri. Kasus ini sudah di tangani Polda Kalimantan Tenah dan Pelaku sudah dalam tahanan Polda.

Dinas PPKBPPPAPM Kota Palangka Raya juga aktif memberikan penyuluhan setiap bulan di 5 (lima) Kecamatan di yang ada di Kota Palangka Raya, dengan memberikan penyuluhan kepada ibu-ibu PKK kecamatan untuk menyampaikan kepada PKK di Desadesanya dan menyampaikan kepada orang tua agar anak wajib dilindungi dari tindakan kekerasan dan penelantaran dari orang tua kebanyakan masalah orang tua yang tidak harmonis dalam membina rumah tangga dan ibu bapaknya sedang bertengkar, rata- 
rata anak yang menjadi sasaran kemarahan orangtuanya.

\section{Dinas PPKBPPPAPM Kota}

Palangka Raya juga bekerja sama dengan instansi-Instansi terkait, Organisasi kemasyarakatan salah satunya POSBAKUM 'Aisyiyah Kalimantan Tengah dalam memberikan penyuluhan. Antusias peserta sangat baik dan berharap agar kegiatan seperti ini dapat terus dilaksanakan selanjutnya. Dalam memberikan penyuluhan dalam situasi pandemi covid-19 ini protokol kesehatan sangat ketat dijalankan.

Kabid Pemberdayaan

Perempuan dan Anak Dinas PPKBP3APM

Kota Palangka Raya juga menambahkan dalam memberikan perlindungan dan pemberdayaan perempuan selain penyuluhan-penyulan tentang ketahanan keluarga juga mengadakan pelatihanpelatihan keterampilan kepada Ibu-ibu dalam rangka meningkatkan ekonomi masyarakat di tengah Pandemi covid-19, seperti keterampilan ayaman dari Rotan, membuat Kue khas Kalimantan, memberikan pelatihan membuat kemasan makanan ringan untuk oleh-oleh. Tentunya pelatihan-pelatihan ini mengikuti standar protokol kesehatan.

Simpulan

Peranan Posbakum 'Aisyiyah Kalimantan Tengah dalam pendampingan di masa Pandemi Covid-19, baik litigasi maupun non litigasi sangat membantu masyarakat. Kebanyakan dari mereka beranggapan pelayanan Posbakum Aisyiyah adalah baik, karena dapat membantu masyarakat yang hendak menyelesaikan perkaranya terutama masyarakat tidak mampu dan masih belum faham dengan proses hukum. Peran Posbakum sangat membantu penyelesaian hukum di masyakarat terutama di masa pandemi covid - 19 yang menjadi korban kekerasan fisik mapun non fisik. Penyelesaian hukum dengan bantuan Posbakum memuaskan bagi klien.

Kebijakan pemerintah kota Palangkaraya terhadap perlindungan hukum perempuan dan anak di tengah pandemi covid-19 sangat baik. Pemerintah kota melalui Dinas PPKBPPPAPM Kota Palangka Raya, dalam memberikan perlindungan dan pemberdayaan perempuan, melakukan penyuluhanpenyulan tentang ketahanan keluarga juga mengadakan pelatihan-pelatihan keterampilan kepada Ibu-ibu dalam rangka meningkatkan ekonomi masyarakat di tengah Pandemi covid-19, sehingga perempuan dalam rumah tangga menjadi mandiri, tidak bergantung pada suami, kesejahteraan keluarga meningkat dan kesehatan lebih terpelihara, sehingga kekerasan fisik maupun non fisik dapat terhindarkan

\section{Rekomendasi dan Saran}

$$
\text { Guna meningkatkan peranan }
$$

Posbakum Aisyiyah Kalimantan Tengah, diharapkan bagi pemerintah kota Palangka 
Sanawiah dan Rita rahmaniati Peran Pos Bantuan Hukum 'Aisyiyah Kalimantan Tengah Terhadap Perlindungan ukum Perempuan dan Anak dimasa Pandemi Covid-19

Raya maka Posbakum Aisyiyah agar dapat segera terakreditasi, sehingga ruang gerak tidak lagi terbatas dan dapat lebih dikenal masyarakat di kota Palangka Raya tetapi juga seluruh kabupaten di Kalimantan Tengah. 


\section{DAFTAR PUSTAKA}

\section{Buku}

Al-Qur'an dan Terjemahnya. 20II, Jakarta:

Departemen Agama Republik Indonesia.

Arif Berda Nawawi, 200I. Masalah Penegakan Hukum dan Kebijakan Penanggolangan Kejahatan, Bandung: Citra Aditya Bakti.

Ahmad Rifai, 20l0. Penemuan Hukum Oleh Hakim dalam Perspektif hukum Progresif, Jakarta: Sinar Grafika.

Atmosudirjo Prajudi, 2002. Teori Hukum, Jakarta: Kawan Pustaka.

Ali Zainuddin, 2005, Sosiologi Hukum, Jakarta. Cruz, Peter De, Perbandingan Sistem Hukum

(Common Law, Civil Law dan Socialist

Law) Bandung : Nusa Media : 2010.

Departemen Pendidikan Nasional. 2005.

Kamus Besar Bahasa Indonesia. Jakarta:

Balai Pustaka.

E. Fernando M, Manulang, Menggapai Hukum Berkeadilan, Jakarta: Kompas 2007.

Fuady Munir, 2007. Sosisologi kontemporer Interaksi kekeuasaan, dan masyarakat, Bandung: Cetakan Pertama, PT Citra Aditya Bakti. -, 2002. Perbuatan Melawan Hukum, Jakarta: Citra aditya Bakti.
Majelis Tarjih dan Tajdid. 2018, Himpunan Tarjih Muhammadiyah 3, Penerbitan Suara Muhammadiyah.

Soekanto, Soerjono, Pengantar $P$ enelitian Hukum, UI-Press, Jakarta, 1986

Soemitro Hanitijo, Ronny,Masalah-masalah sosiologi hukum, Sinar Baru, Bandung, 1984.

Subekti Prof. R., S.H. Pokok-pokok Hukum Perdata, Penerbit Intermasa, Jakarta 1987. Cet XXI.

Sugiyono, 20II. Metode Penelitian Kuantitatf Kualitatif Dan R\&D. Bandung: Alfabeta.

Sumaryono, E. Hermeniutik Sebuah Metode Filsafat, Penerbit Kanisius, Yogyakarta, 1993

\section{Undang-undang}

Undang-Undang Dasar NKRI Tahun 1945

Undang-Undang No. 39 tahun 1999, tentang Ha k Asasi Manusia.

Undang-Undang Nomor 16 Tahun 2011 tentang bantuan Hukum Gratis Bagi masyarakat miskin.

Undang-undang No 35 tahun 2014 tentang Perubahan Atas UU Nomor 23 tahun 2002 tentang Perlindungan Anak. 